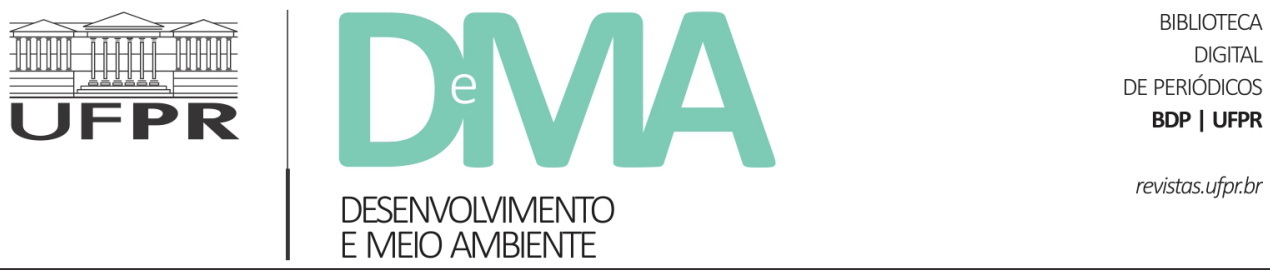

\title{
Infrações ambientais no município do Rio de Janeiro: uma análise das denúncias do ministério público estadual
}

\section{Environmental infringements in the municipality of Rio de Janeiro: an analysis of the complaints of the state public ministry}

\author{
Maria Fernanda Rangel CHEHADI ${ }^{1}$, Jose Geraldo Pereira BARBOSA ${ }^{1,2^{*}}$ \\ ${ }^{1}$ Universidade Federal do Estado do Rio de Janeiro (UNIRIO), Rio de Janeiro, RJ, Brasil. \\ ${ }^{2}$ Universidade Estácio de Sá (UNESA), Rio de Janeiro, RJ, Brasil. \\ *E-mail de contato: jgeraldopb@gmail.com
}

Artigo recebido em 20 de dezembro de 2019, versão final aceita em 6 de agosto de 2020, publicado em 25 de novembro de 2020.

\begin{abstract}
RESUMO: O presente trabalho teve como objetivo principal analisar as denúncias de infrações ambientais enviadas pelo Ministério Público Estadual (MPE) à Prefeitura da Cidade do Rio de Janeiro no ano de 2018. O objetivo secundário do trabalho foi comparar as irregularidades ambientais encontradas em cada uma das 33 regiões administrativas (RA) do município com dados de progresso social e expectativa de crescimento populacional de cada RA para tentar encontrar correlações que pudessem explicar a dinâmica das denúncias no Município. A pesquisa de abordagem quali-quanti foi classificada como uma investigação ex post e documental a partir de um banco de dados municipal contendo as queixas de violações ambientais enviadas pelo MPE, e outras informações públicas sobre as regiões administrativas. A partir destas informações, constatou-se que o desmatamento e o loteamento irregular do solo representam quase metade das denúncias. Os resultados de regressões lineares efetuadas sugerem que, quanto maior a expectativa de aumento populacional da RA, mais denúncias ocorrem, o que pode ser explicado por ações de especulação imobiliária. Verifica-se também que regiões com altos indicadores de "moradia" e "segurança" levam seus moradores a uma maior propensão a denunciar as irregularidades. Por outro lado, constatou-se que, no caso das áreas onde a população tem baixa renda e pouco acesso à educação, a quantidade de queixas é muito baixa ou nula. Em função das distorções acima apresentadas, o presente estudo propõe uma distribuição das 33 regiões administrativas em seis grupos, a partir de níveis de renda, quantidade de denúncias, vulnerabilidade ambiental e indicadores de progresso social de cada RA, diferente da presente distribuição das RA em cinco áreas de planejamento (AP), divisão territorial feita basicamente por proximidade geográfica. O agrupamento proposto possibilita uma análise mais adequada das infrações ambientais por permitir uma visão mais abrangente das diversas questões (renda, saúde, segurança, educação entre outras) envolvidas neste fenômeno.
\end{abstract}


Palavras-chave: administração municipal; impactos ambientais; planejamento urbano; desenvolvimento sustentável.

ABSTRACT: The present work had as main objective to analyze the complaints of environmental infractions sent by the State Public Prosecutor (MPE) to the City Hall of Rio de Janeiro in 2018. The secondary objective of the work was to compare the environmental irregularities found in each of the 33 administrative regions (AR) of the municipality with data of social progress and population growth expectation of each RA to try to find correlations that could explain the dynamics of complaints in the Municipality. The quali-quanti survey was classified as an ex post and documentary investigation from a municipal database containing complaints of environmental violations sent by the MPE, and other public information about administrative regions. From this information, it was found that deforestation and irregular distribution represent almost half of the complaints. The results of linear regressions suggest that the higher the expectation of population increase of $\mathrm{AR}$, the more complaints, which can be explained by actions of real estate speculation. It is also found that regions with high indicators of "housing" and "security" lead their residents to a greater propensity to report irregularities. On the other hand, it was found that in the areas where the population has low income and little access to education, the number of complaints is very low or zero. Due to the distortions presented above, the present study proposes a distribution of the 33 administrative regions in 6 groups, based on income levels, number of complaints, environmental vulnerability and social progress indicators of each AR, different from the present distribution of AR in 5 planning areas (PA), territorial division made basically by geographical proximity. The proposed grouping allows a more adequate analysis of environmental infractions by allowing a broader view of the various issues (income, health, safety, education, among others) involved in this phenomenon.

Keywords: municipal administration; environmental impacts; urban planning; sustainable development.

\section{Introdução}

O meio ambiente é conceituado pela Lei $\mathrm{n}^{\circ}$ 6.938 , de 31 de agosto de 1981 , artigo $3^{\circ}$, inciso I, como "conjunto de condições, leis, influências e interações de ordem física, química e biológica que permite, abriga e rege a vida em todas as suas formas". Além da complexidade associada a essa definição, Bursztyn \& Bursztyn (2012, p. 44) ressaltam a vulnerabilidade de sistemas ambientais frente a determinados danos ecossistêmicos e a dificuldade de restaurar e repor a natureza em certas situações. Por esta ótica, o princípio fundamental que rege o Direito Ambiental é o da prevenção, "uma vez que os danos ambientais, na maioria das vezes, são irreversíveis e irreparáveis" (Fiorillo, 2012, p. 126).
Somado a isso, a Constituição Federal Brasileira prevê, no artigo $225^{\circ}$, que o meio ambiente ecologicamente equilibrado é um direito de todos, além de ser essencial à sadia qualidade de vida e impõe a necessidade de defendê-lo e preservá-lo para as presentes e futuras gerações, competência essa atribuída ao Poder Público e à coletividade. (Brasil, 1988)

No município do Rio de Janeiro, a Gerência de Monitoramento e Fiscalização Ambiental (GMFA) da Subsecretaria Municipal de Meio Ambiente da Cidade do Rio de Janeiro (SUBMA) é o órgão responsável pela apuração das infrações ambientais. Esta Gerência coordena: quatro Subgerências de Fiscalização, que apuram in loco as denúncias recebidas; e quatro Gerências de Monitoramento. A atuação da GMFA consiste em "acompanhar a 
execução e apresentar propostas sobre o programa de monitoramento da qualidade dos recursos ambientais do Município, visando à proteção contra os diversos tipos de poluição e degradação e realizar vistorias e aplicar as sanções administrativas previstas em lei" (Rio de Janeiro, 2017a). Atualmente a Gerência de Monitoramento e Fiscalização Ambiental recebe, de diversos órgãos, mais de 500 denúncias por ano, excluindo os casos de poluição sonora, sendo a maior parte desses ofícios oriundos do Ministério Público do Estado.

O presente trabalho teve como objetivo principal analisar as denúncias de infrações ambientais enviadas pelo Ministério Público Estadual (MPE) à Prefeitura da Cidade do Rio de Janeiro no ano de 2018. É importante destacar que o termo "denúncias" se refere aos ofícios que o MPE envia à Prefeitura com o objetivo de dar conhecimento sobre possíveis infrações e pedir esclarecimentos. A análise consistiu na identificação dos locais e dos tipos de infrações para mapear a incidência destas nas regiões administrativas do município. Buscou-se entender qual tipo de infração tem mais incidência em quais regiões e observar se existem áreas onde há um comportamento similar.

O objetivo secundário foi analisar a relação entre os diversos tipos de denúncias de irregularidades ambientais e características próprias de cada região administrativa, tais como: os doze indicadores do Índice de Progresso Social (IPS) e a expectativa de aumento da população de cada região administrativa.

Foram excluídas as denúncias do tipo "Poluição Sonora", pois de acordo com o Decreto n. ${ }^{\circ}$ 43.372, de 30 de junho de 2017, apenas competem à Subsecretaria de Meio Ambiente os casos de poluição sonora que decorram: "I - De atividades passíveis de licenciamento ambiental; II - De Instalações passíveis de licenciamento pela Gerência de Engenharia Mecânica da RIOLUZ." Assim, a atuação da Subsecretaria torna-se excepcional (Rio de Janeiro, 2017b). A Região Administrativa de Paquetá também foi excluída do presente trabalho devido à ausência de informações sobre esta região.

Entende-se que os resultados deste trabalho são relevantes para os gestores da Prefeitura do Rio de Janeiro pois podem auxiliar na formulação de políticas públicas ambientais.

\section{Fundamentação teórica}

Segundo a Constituição Federal, a competência para legislar sobre a proteção do meio ambiente é concorrente, de modo que a União é responsável por editar as normas gerais, e os Estados e Distrito Federal suplementam-nas. Compete então ao Município legislar sobre meio ambiente "no limite de seu interesse local e desde que tal regramento seja harmônico com a disciplina estabelecida pelos demais entes federados" (STF, 2015)

Em seu artigo $23^{\circ}$, a Carta Magna impõe a todos os entes federados o dever de: "proteger o meio ambiente e combater a poluição em qualquer de suas formas" e "preservar as florestas, a fauna e a flora". A Lei Complementar n. ${ }^{\circ}$ 140/ 2011 (Brasil, 2011), ao regulamentar o parágrafo único do art. 23, atribui diversas ações administrativas aos $\mathrm{Mu}-$ nicípios $\left(\right.$ art. $9^{\circ}$ ), como a de fiscalizar e controlar as irregularidades de âmbito local - "qualquer alteração direta ou indireta das propriedades (...) do meio ambiente, (...) dentro dos limites do Município". (CONEMA, 2012). 
Fernandes et al. (2012, p. 133) conceituam o termo gestão ambiental como "a função de solucionar ou administrar os problemas socioambientais, equilibrando as correlações de forças existentes na sociedade, apoiadas em um sistema de informação, monitoramento e avaliação das políticas". Câmara (2013, p. 142) destaca a importância de conhecer a dinâmica destes conflitos, para que haja a promoção do desenvolvimento sustentável no Brasil, "por meio de políticas públicas efetivas, sem o caráter utilitarista e predatório ao meio ambiente que acompanha o país desde a época colonialista".

Segundo Hannigan (2009 apud Borinelli, 2011), são características intrínsecas que dificultam a gestão ambiental: a complexidade e incerteza; a irreversibilidade dos danos; os conflitos de valores e interesses; e a multidisciplinariedade que este tema exige. Conforme Borinelli (2011), este último atributo destaca-se, pois uma boa gestão ambiental depende de buscar o conhecimento de outras áreas, como, por exemplo as ciências sociais e naturais.

Honda et al. (2015) afirmam que o planejamento é imprescindível para a boa gestão ambiental, e sua ausência prejudica a continuidade dos serviços públicos. Também existem: lacunas nas práticas de monitoramento e avaliação de implementação destas políticas, que geram obstáculos à efetivação de seus objetivos (Fernandes et al., 2012); e lacunas teóricas, na formulação de indicadores que possam servir de base para o tomador de decisão.

Pizella (2015, p. 643) afirma que as cidades são responsáveis pelo desenvolvimento das "políticas públicas de resíduos sólidos, drenagem urbana, abastecimento e, em diversos casos, de coleta e tratamento de esgotos, assim como de criação e manutenção de áreas verdes", o que explica o papel relevante dos órgãos municipais na proteção ao ambiente.

Contudo, os Municípios enfrentam dificuldades nestas tarefas, devido a alguns obstáculos, como a insuficiência de recursos e estrutura inadequada. Quanto à falta de recursos financeiros, Nazareth (2018) revela que, apesar de a Constituição atribuir autonomia administrativa aos Municípios para a gestão ambiental, ela não garantiu as fontes de financiamento necessárias à execução destas políticas. A autora (2018, p. 214) também destaca as dificuldades de qualificação de pessoal. Em relação aos problemas estruturais, o "investimento em infraestruturas e serviços básicos (água, eletricidade, saneamento, resíduos sólidos), transportes, regularização da propriedade fundiária e moradia digna e acessível" permanece ainda aquém do desejado. Estes obstáculos dificultam a redução da desigualdade e o oferecimento de um ambiente propício para a prosperidade econômica, social e ambiental (Nazareth, 2018, p. 212).

As autoras Nunes \& Bastos (2018) realçam que a fiscalização deficiente por parte dos órgãos públicos não consegue impedir atividades que impactam diretamente o meio ambiente urbano (lançamento de substâncias nocivas em curso hídrico, despejo inadequado de resíduos sólidos), o que impulsiona ainda mais os problemas ambientais. Souza (2015, p. 31) revela que o Estado nem sempre trata os infratores ambientais da mesma maneira, aplicando o discurso de proteção ao meio ambiente apenas para remover a população das áreas onde "a favela, informal e pobre, 'enfeia' a parte bonita da Cidade". O autor (2015) cita uma comunidade localizada entre o bairro de Jacarepaguá e da Barra da Tijuca, onde o Prefeito, à época, utilizou como argumento para remoção de quinhentas famílias a 
necessidade de preservar as margens da Lagoa de Jacarepaguá. Entretanto, Souza (2015) revela que a Lagoa já estava há muitos anos imprópria para o banho e a pesca devido à poluição causada em grande medida pelo esgoto doméstico nela despejado in natura pelos "condomínios exclusivos" da região.

Para Stanganini \& Lollo (2018, p. 119), “o crescimento das cidades brasileiras nas últimas décadas tem causado o aumento da degradação ambiental nas áreas urbanas" e, consequentemente, aumenta a pressão sobre os recursos naturais, ocasionando uma elevada demanda por serviços e por uma infraestrutura urbana adequada do ponto de vista ambiental. Além disso, a maioria das cidades não foi projetada para atender a demanda populacional atual, de modo que carecem de infraestrutura para satisfazer a sua gama populacional (Nunes \& Bastos, 2018).

Neste sentido, Stanganini \& Lollo (2018, p. 119) identificam que "a expansão das áreas periféricas está relacionada à procura por habitação em áreas com baixo preço da terra, provocando um aumento das ocupações precárias, como favelas e loteamentos irregulares, em áreas sem infraestrutura e expostas". Como consequência, ocorreram: a intensificação da concentração da riqueza e o aumento das desigualdades (Malta et al., 2017); e a ocupação desordenada do solo, que exige ações para conter a degradação ambiental e para a prevenção e gestão de riscos de desastres (Nazareth, 2018).

Conforme Bursztyn \& Bursztyn (2012), os principais impactos ambientais das aglomerações urbanas são: deficiência dos serviços saneamento ambiental; poluição industrial de diversas naturezas; poluição do ar; poluição sonora; ocupação de encostas e de fundos de vale; e pouca disponibilidade e manutenção inadequada de áreas verdes. Estes impactos originam denúncias de irregularidades ambientais, que serão analisadas no presente trabalho. Estudá-las é necessário para compreender mais completamente o impacto e a dinâmica das instituições e políticas ambientais (Borinelli, 2011). Bento et al. (2018, p. 485) destacam a importância da governança ambiental, que pode acontecer tanto por meio da participação da população no processo decisório quanto no cotidiano, “em que o cidadão se apropria e passa a ter consciência da sustentabilidade urbana, e reflete isso tanto em suas ações e práticas como em princípios e valores que serão passados adiante para as gerações futuras". Segundo Aguiar (2019), essa participação democrática na gestão ambiental cria um fluxo de informações contínuo e eficaz. Nunes \& Bastos (2018) também afirmam que a incorporação da educação ambiental é capaz de mudar a percepção do cidadão, de modo que este perceba que faz parte do todo o contexto da natureza.

\section{Metodologia}

O presente trabalho teve como objetivo principal analisar as denúncias de infrações ambientais enviadas pelo Ministério Público Estadual (MPE) à Prefeitura da Cidade do Rio de Janeiro no ano de 2018. O objetivo secundário foi analisar a relação entre os diversos tipos de irregularidades ambientais e 13 características próprias de cada região administrativa do município, quais sejam: os 12 indicadores do Índice de Progresso Social (IPS) e a expectativa de aumento da população de cada região administrativa. Os quantitativos de denúncias e as características de cada RA podem ser vistas nos Anexos 1 e 2 respectivamente. 
A abordagem escolhida foi quali-quanti, pois, se por um lado, de acordo com Minayo \& Sanches (1993), a pesquisa quantitativa utiliza linguagem matemática para descrever as causas de um fenômeno e as relações entre as variáveis, buscando descobrir a relação entre fatos e variáveis, por outro lado, a pesquisa qualitativa justifica-se, de acordo com Creswell (2016), pela necessidade de maior profundidade de análise, com muitas variáveis e poucos casos; pela coleta de dados em ambiente natural; por ter o pesquisador como instrumento fundamental, uma vez que os dados serão coletados pessoalmente; por analisar e buscar entender uma questão social; pela análise de dados indutiva, construída a partir das particularidades e evoluindo para os temas gerais, valendo-se das interpretações realizadas pelo pesquisador acerca do significado dos dados (Creswell, 2016). Quanto aos fins, a pesquisa é caracterizada como explicativa, porque pretende identificar os fatores que contribuem para a ocorrência e o desenvolvimento de um determinado fenômeno, neste caso, as infrações ambientais.

De acordo com Vergara (1998), quanto aos meios, a pesquisa é classificada como documental e investigação ex post facto. Documental pois a investigação foi feita com base em documentos. No caso das infrações ambientais, analisou-se o banco de dados da GMFA, em que constam as informações dos ofícios enviados pelo MPE. No que diz respeito aos indicadores de progresso social, expectativa de crescimento populacional, renda e demais informações sobre as regiões administrativas, foram utilizados dados coletados em documentos públicos. Também é classificada como investigação ex post facto, pois refere-se a fatos já ocorridos, quando não é possível manipular e controlar as variáveis. As denúncias de irregularidades ambientais foram classificadas por tipo conforme a Tabela 1 .

TABELA 1 - Tipos de Infrações.

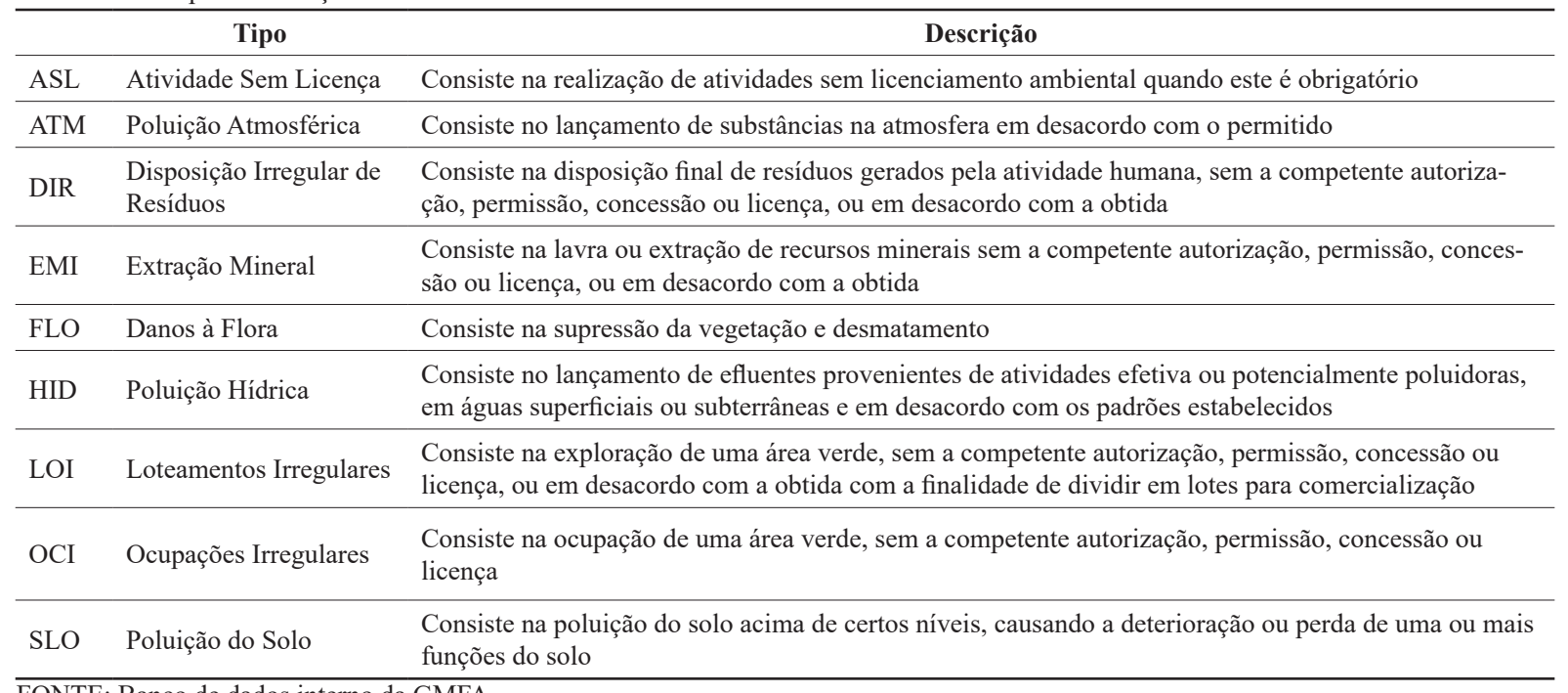

FONTE: Banco de dados interno da GMFA. 
Para cada região administrativa foram obtidas as quantidades de denúncias de infrações ambientais. Por sua vez, as 33 regiões administrativas foram caracterizadas por sua expectativa de aumento populacional e pelos indicadores que compõem o Índice de Progresso Social (IPS). Esse índice utiliza 12 variáveis, distribuídas em três dimensões, que são: Necessidades Humanas Básicas: Nutrição e Cuidados Médicos Básicos, Água e Saneamento, Moradia e Segurança Pessoal; Fundamentos do Bem-estar: Acesso ao Conhecimento Básico, Acesso à Informação E Comunicação, Saúde e Bem-estar, Sustentabilidade dos Ecossistemas; e, Oportunidades: Direitos Individuais, Liberdade Individual e de Escolha, Tolerância e Inclusão e Acesso à Educação Superior. As notas de cada variável variam de 0 (pior) a 100 (melhor). Os critérios utilizados para as notas de cada indicador podem ser encontrados em (IPP, 2016). Com relação à expectativa de aumento populacional, os valores foram calculados a partir do estudo elaborado pelo Instituto Pereira Passos (IPP, 2013), o qual fez projeções sobre o crescimento populacional para o ano de 2020, com base nos dados dos Censos Demográficos de 2000 e 2010. Por fim, foram comparados os valores de 2000 e 2010 , obtendo-se então o percentual relativo à projeção de cada RA, conforme a Tabela do Anexo 2.

Inicialmente, foram calculadas as médias, desvios padrões e relação desvio padrão/média de todas as variáveis envolvidas. Na próxima etapa, para verificar a influência de características próprias de cada região administrativa do município do Rio de Janeiro (variáveis explicativas) sobre o número de infrações ambientais em cada região administrativa (variável explicada), utilizou-se a ferramenta de análise de regressão linear múltipla.
Para esta finalidade, foi utilizado o suplemento Análise de Dados do Microsoft Excel 2007, com verificação de valores adequados para R2 ajustado, $\mathrm{F}$ de teste, multicolinearidade e valores-P das variáveis explicativas (estes últimos com nível de significância 0,05).

Em seguida, as RAs foram classificadas quanto aos níveis de renda em "alta renda", "média renda" e "baixa". Finalmente, as regiões administrativas foram separadas em seis grupos. Este agrupamento levou em consideração os níveis de renda das regiões administrativas, quantidade de denúncias, vulnerabilidade ambiental e indicadores de progresso social, o que torna o mesmo mais eficaz do que o agrupamento por AP (divisão territorial feita basicamente por proximidade geográfica) para uma análise dos problemas encontrados por permitir uma visão mais abrangente (holística) das questões envolvidas.

\section{Apresentação e análise dos resultados}

\subsection{O município do Rio de Janeiro}

Atualmente a cidade conta com cinco Áreas de Planejamento (APs), que compreendem 33 Regiões Administrativas (RAs), conforme a Tabela 2.

Apesar de o Município do Rio de Janeiro ser considerado totalmente urbano, ele conta com expressiva cobertura vegetal, o que o categoriza como Área Verde Urbana (Pedreira et al., 2017). A Lei n. ${ }^{\circ}$ 12.651, artigo $3^{\circ}$, inciso XX, (Brasil, 2012), define área verde urbana como: “espaços, públicos ou privados, com predomínio de vegetação, preferencialmente nativa, natural ou recuperada, (...) indisponíveis para construção de moradias, destina- 
dos aos propósitos de recreação, lazer, melhoria da qualidade ambiental urbana, proteção dos recursos hídricos, manutenção ou melhoria paisagística, proteção de bens e manifestações culturais".

O Plano Municipal de Conservação e Recuperação da Mata Atlântica do Rio de Janeiro (PMMA-Rio) tem como diretriz o "mapeamento e monitoramento de áreas estratégicas para a recuperação ambiental" (Rio de Janeiro, 2014, p. 245). A Tabela
3 apresenta as reduções na cobertura de área verde (vegetal) das áreas de planejamento, no período de janeiro de 2017 a junho de 2018. "Adotou-se um conceito abrangente de áreas verdes, considerando áreas públicas e privadas, com cobertura arbórea ou herbácea, permanente ou temporária" (GMFA-7, 2018). A Tabela 4, por sua vez, apresenta os dez (10) bairros com maior cobertura de Mata Atlântica (Rio de Janeiro, 2016).

TABELA 2 - Regiões Administrativas por AP.

\begin{tabular}{lllll}
\hline \multicolumn{1}{c}{ AP 1 } & \multicolumn{1}{c}{ AP 2 } & AP 4 & AP 5 \\
& & Ramos & \\
& & Penha & \\
& & Inhaúma & \\
Portuária & Botafogo & Meier & Santa Cruz \\
Centro & Vila Isabel & Irajá & Jacarepaguá & Bangu \\
Rio Comprido & Copacabana & Il. do Governador & Campo Grande \\
São Cristóvão & Lagoa & Anchieta Tijuca & Guaratiba \\
Santa Teresa & Tijuca & Complexo do Alemão de Deus & Realengo \\
Il. De Paquetá & Rocinha & Pavuna & & \\
& & Jacarezinho & & \\
& & Maré & & \\
\end{tabular}

FONTE: Prefeitura do Rio de janeiro, (Rio de Janeiro, 2017c). https://www.data.rio/datasets/3f105a10dcf7475eae69b2514b9d6262

TABELA 3 - Alterações na cobertura vegetal nas áreas de planejamento - janeiro de 2017 a junho 2018.

\begin{tabular}{ccc}
\hline AP & ÁREA reduzida em m & \% na redução total \\
\hline AP1 & 1.463 & $0,10 \%$ \\
AP2 & 18.846 & $0,70 \%$ \\
AP3 & 123.642 & $4,60 \%$ \\
AP4 & 624.610 & $23,40 \%$ \\
AP5 & 1.900 .861 & $71,20 \%$ \\
Total & 2.669 .422 & $100,00 \%$ \\
\hline
\end{tabular}

FONTE: Programa de Monitoramento da Cobertura Vegetal - SUBMA (GMFA-7, 2018). http://www.rio.rj.gov.br/dlstatic/10112/6438610/4221813/75ProgramadeMonitoramentodaCoberturaVegetal.pdf
A Área de Planejamento 1 (AP1) é a menor AP. Nesta região concentram-se repartições públicas, setores financeiros e serviços e diversificado comércio. Esse caráter comercial foi intensificado ao longo dos anos e, apesar de ter perdido quase $27 \%$ de população entre 1970 e 2000, ainda atrai quase um milhão de pessoas que trabalham nesta região (Rio de Janeiro, 2006).

A Área de Planejamento 2 (AP2), também conhecida como Zona Sul, estende-se entre os morros do maciço da Tijuca e as praias oceânicas, até a entrada da Baía de Guanabara. Esta AP representa apenas $8,2 \%$ do território, entretanto, é muito populosa. O bairro Alto da Boa Vista, situado na AP2, conforme a Tabela 4, concentra parte significativa 
TABELA 4 - Top10 Bairros com maior área de cobertura de Mata Atlântica, em hectares.

\begin{tabular}{ccccc}
\hline & AP & Bairro & RA & $\begin{array}{c}\text { Área } \\
\text { (ha) }\end{array}$ \\
\hline 1 & AP 5 & Guaratiba & Guaratiba & 6.458 \\
2 & AP 4 & Jacarepaguá & Jacarepaguá & 4.732 \\
3 & AP 5 & Campo Grande & Campo Grande & 3.404 \\
4 & AP 2 & Alto da Boa Vista & Tijuca & 2.837 \\
5 & AP 4 & Vargem Grande & Barra da Tijuca & 2.718 \\
6 & AP 5 & Santa Cruz & Santa Cruz & 1.943 \\
7 & AP 5 & Bangu & Bangu & 988 \\
8 & AP 4 & R. dos Bandeirantes & Barra da Tijuca & 939 \\
9 & AP 4 & Barra da Tijuca & Barra da Tijuca & 888 \\
10 & AP 4 & Vargem Pequena & Barra da Tijuca & 744 \\
\hline
\end{tabular}

FONTE: Mapeamento da Cobertura e do Uso das Terras do Rio de Janeiro - (Rio de Janeiro, 2016). https://www.rio.rj.gov.br/web/smac/ exibeconteudo? id=2367968\#: :text=O\%20mapeamento $\% 20 \mathrm{da} \% 20$ cobertura $\% 20$ vegetal,os $\% 20$ conhecimentos $\% 20$ das $\% 20$ ci $\%$ C3\%AAncias\%20naturais.

da Mata Atlântica da Cidade, o que o configura como o quarto bairro com mais área verde. Esta é a área onde há maior concentração de turistas, sendo conhecida por ter hotéis, restaurantes, cinemas e teatros. A maior parte da população de alta renda da cidade está nesta região, apresentando elevados padrões de infraestrutura (Rio de Janeiro, 2014, p. 16).

A Área de Planejamento 3 (AP3), conhecida como o "Subúrbio Carioca" ou "Zona Norte", corresponde a $16,6 \%$ do território municipal (Rio de Janeiro, 2006). Trata-se de uma região com grande adensamento populacional, onde há uma boa infraestrutura e uma ampla rede de serviços, "concentra $42 \%$ dos habitantes do município e $50 \%$ do total da população residente em favelas" (Rio de Janeiro, 2014, p. 17).
A Área de Planejamento 4 (AP4) corresponde a $24 \%$ da área total da cidade. Trata-se de extensa área de baixada, mantida durante muito tempo preservada, sem inserção na malha urbana, em função das próprias características geográficas que the dificultavam o acesso (Rio de Janeiro, 2006). Todavia, a partir dos anos 70, a AP4 passou por um "processo acelerado de urbanização e refuncionalização, abrigando setores de população de classe social de alta e média rendas e atraindo diversas empresas, constituindo-se, atualmente, como importante polo de serviços da cidade" (Rio de Janeiro, 2014, p. 18). $\mathrm{O}$ crescimento da malha urbana e o desmatamento das encostas moldam a região.

A Área de Planejamento 5 (AP5), também conhecida como "Zona Oeste", corresponde a 48,4\% do Município, porém possui baixa concentração de habitantes. Atualmente, a AP5 é a que mais cresce em população. Entretanto a maior parte encontra-se em loteamentos irregulares e favelas (Rio de Janeiro, 2014, p. 20), o que gerou redução das áreas naturais. Isso demostra a necessidade de promover a expansão desta AP de forma ambientalmente equilibrada e fornecendo infraestrutura às pessoas que residem nesta área.

\subsection{Análise dos resultados}

Foram analisadas trezentas e setenta e três (373) denúncias de infrações ambientais enviadas pelo Ministério Público Estadual à Subsecretaria Municipal de Meio Ambiente durante o ano de 2018. Estas denúncias foram classificadas em nove tipos, conforme classificação constante da Quadro 1 no capítulo Metodologia. 
4.2.1. Estatística descritiva das denúncias por Área de Planejamento (AP)

A Figura 1 representa a distribuição das denúncias por tipo de irregularidades ambientais, enquanto a Figura 2 permite perceber como as infrações ambientais se distribuem de maneira irregular nas Áreas de Planejamento.

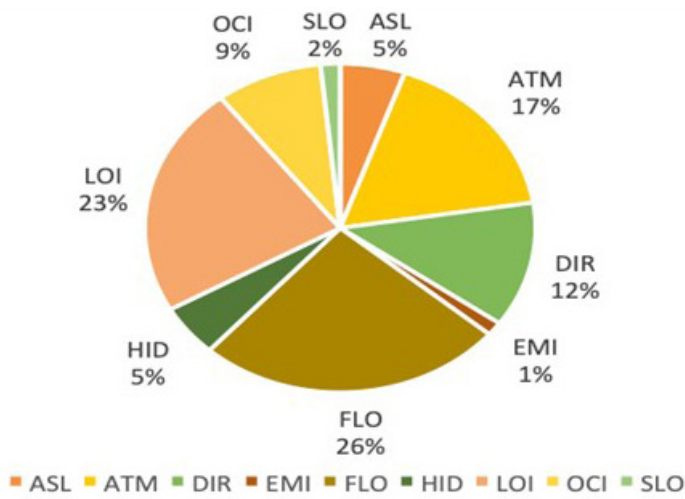

FIGURA 1 - Distribuição das Infrações por tipo. FONTE: Os autores.

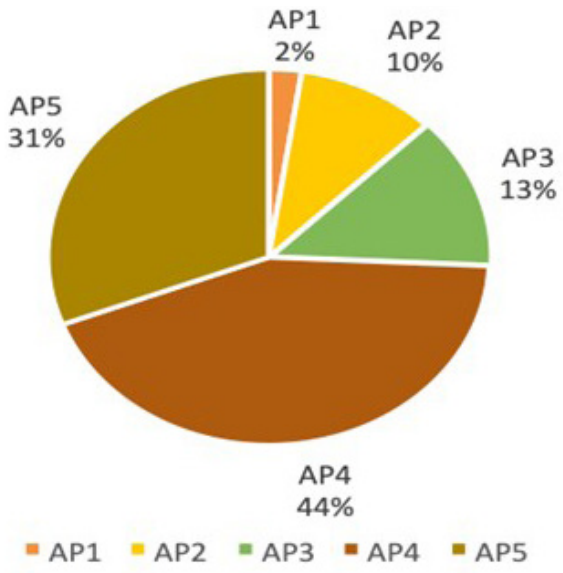

FIGURA 2 - Total de Infrações por AP. FONTE: Os autores.
A Figura 3, por sua vez, mostra quais tipos de infração ocorrem mais em cada AP. A AP 1 apresenta um comportamento homogêneo, de modo que apresenta uma quantidade de denúncias abaixo da média na maioria dos tipos de infrações. No mesmo sentido, Malta et al. (2017, p. 3939) classificam "metade da área da AP 1 como média vulnerabilidade socioambiental (48,3\%), 27,4\% como baixa vulnerabilidade socioambiental, $23,6 \%$ como alta vulnerabilidade socioambiental, e $0,7 \%$ como vulnerabilidade socioambiental muito alta".

Os casos de poluição hídrica da AP1 costumam ser devidos à Baía de Guanabara, onde estão localizados: o porto da cidade e as barcas (importante meio de transporte aquático). Neste sentido, o Plano Municipal da Mata Atlântica da Cidade (Rio de Janeiro, 2014) afirma que há uma "histórica e constante degradação do seu sistema natural, com poluição da água através de lançamento de efluentes líquidos e resíduos sólidos".

Em relação à Poluição Atmosférica (ATM), as Áreas 2, 3, 4 e 5 apesentam um comportamento semelhante, conforme a Figura 3 acima. Isso ocorre, principalmente, porque este tipo de irregularidade pode continuar ocorrendo e se intensificando mesmo quando grande parte dos recursos naturais (rios, florestas, etc.) já foi danificado. É o caso das AP2 e AP3, onde, apesar de existirem poucas áreas verdes florestais remanescentes (com exceção do bairro do Alto da Boa Vista - o quarto bairro com maior concentração de área verde da Cidade - Tabela 4), apresentam altos índices destes tipos de infração.

Há muitas denúncias do tipo Disposição Irregular de Resíduos (DIR), estas representam 12\% do total. Logo, é um tipo comum de infração ambiental, principalmente em regiões onde a coleta de lixo não é feita regularmente ou não é suficiente. As AP 


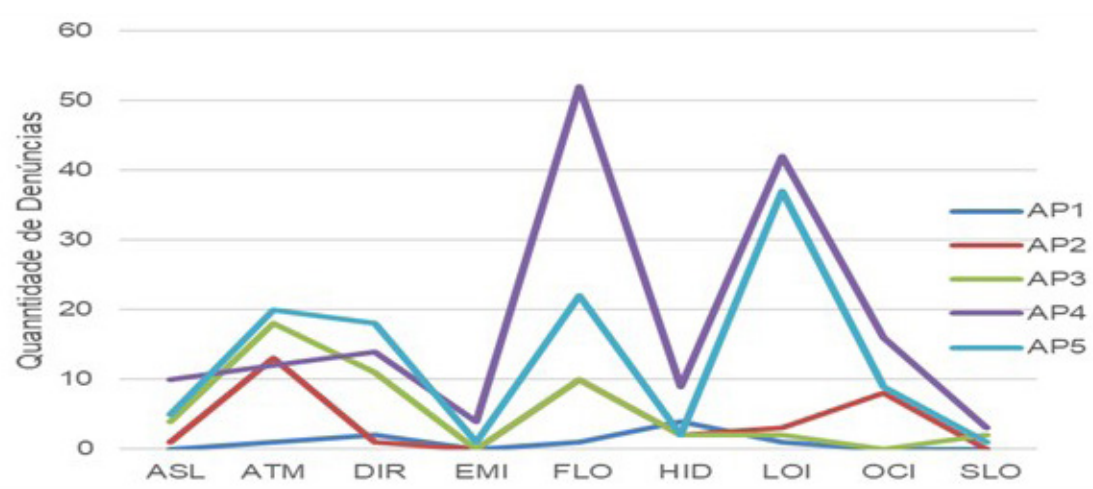

FIGURA 3 - Tipos de infração X áreas de planejamento.

FONTE: Os autores.

3, 4 e 5 são as que mais sofrem com esse tipo de infração. Existem também reclamações de lixões que não possuem medidas construtivas para proteção ambiental conforme as Normas Técnicas. De acordo com o PMMA-Rio (Rio de Janeiro, 2014), em algumas áreas da Cidade, moradores realizam queimadas de lixo. Esta prática, além de poder gerar incêndios florestais, polui a atmosfera. A disposição incorreta dos resíduos "pode agravar os riscos de alagamentos e deslizamentos, devido à presença de sobrecargas nas encostas, ao entupimento dos bueiros e ao assoreamento dos canais, sendo que os resíduos sólidos transportados pelos rios e pelo sistema de drenagem podem atingir os oceanos" (Bernardino \& Franz, 2016, p. 232).

As denúncias de Danos à Flora (FLO) foram as mais comuns no período analisado, representando $26 \%$ do total. Assim como na maioria dos tipos analisados, a distribuição deste tipo não se deu de maneira homogênea. As AP 4 e 5 ficaram acima da média de 19 infrações por área de planejamento (95 - número total de infrações do tipo FLO na tabela do Anexo 1, dividido por 5 - número de AP). É possível observar também que a Área de Planeja- mento 4 apresenta mais da metade (52) das denúncias registradas. No mesmo sentido, o PMMA-Rio (Rio de Janeiro, 2014, p. 18) afirma que "O maciço da Pedra Branca (um dos principais da AP4) vive atualmente um acelerado processo de desenvolvimento das atividades urbanas em seu entorno e de expansão da degradação do ecossistema florestal". Apesar de existir Parque Estadual nesta região, o desmatamento continua avançando. A Prefeitura do Rio de Janeiro busca, por meio de mutirões, reflorestar as áreas degradadas. Entretanto, este projeto enfrenta algumas dificuldades, uma delas é a "violência relacionada às atividades do tráfico de drogas e das milícias que controlam muitas dessas regiões" (Rio de Janeiro, 2014, p. 165).

Quanto aos casos de Poluição Hídrica (HID), nota-se que é baixa a incidência deste tipo de denúncia (5\%). Entretanto, o INEA (INEA, 2019) verificou que, dentre as 34 estações de amostragem de qualidade de água das bacias hidrográficas localizadas na cidade - água coletada antes do tratamento - apenas três estão apropriadas para tratamento convencional visando ao abastecimento público. Para as demais, torna-se necessário um tratamento 
mais avançado. O PMMA-Rio (Rio de Janeiro, 2014, p. 76) verificou que: "o médio e baixo curso dos rios não apresentam mais as suas características naturais por se encontrarem em áreas densamente urbanizadas, o que favorece a ocorrência de enchentes" e os tornam suscetíveis ao lançamento de efluentes provenientes de atividades efetiva ou potencialmente poluidoras em desacordo com os padrões estabelecidos.

Os Loteamentos Irregulares (LOI) e Ocupações Irregulares (OCI) são ocupações em locais irregulares, ou as invasões não estão de acordo com as normas de licenciamento estabelecidas. Estes tipos de denúncias devem ser analisados paralelamente. As denúncias OCI representam 9\% do total e estão distribuídas nas AP 2, 4 e 5. Estas costumam ser de construções em áreas proibidas (Áreas de Proteção Permanente, por exemplo), onde não há infraestrutura e segurança para os próprios moradores, uma vez que são "construções em locais de encostas, margens de rios, lagoas, brejos e de infraestrutura precária com falta de saneamento básico, abastecimento de água e coleta de lixo" (Rio de Janeiro, 2014, p. 83).

As denúncias de loteamento irregular representam $23 \%$ do total de infrações, sendo o segundo tipo de infração de maior incidência. As AP 4 e 5 são as que se destacam, concentrando $92 \%$ das queixas de LOI. Nos relatos enviados à GMFA, geralmente, a área já foi desmatada e está sendo dividida, algumas inclusive usam retroescavadeiras, revelando que, em alguns casos, as divisões são feitas com fins lucrativos. Stanganini \& Lollo (2018, p. 119) afirmam que "a expansão das áreas periféricas está relacionada à procura por habitação em áreas com baixo preço da terra, provocando um aumento das ocupações precárias, como favelas e loteamentos irregulares, em áreas sem infraestrutura e expostas a riscos". A AP 4, a partir da década de 1990, tornou-se um "espaço preferencial para a expansão imobiliária, impulsionada principalmente pela construção de grandes empreendimentos como os modernos condomínios fechados, habitados por uma população de alto poder aquisitivo" (Rio de Janeiro, 2014, p. 143). Nesta AP, conforme a Tabela 4, estão localizados cinco dos dez bairros com maior cobertura vegetal da Mata Atlântica, o que demostra a necessidade de preservar esta região. $\mathrm{Na}$ AP 5, o crescimento industrial impulsionou os loteamentos irregulares e favelas da região. Conforme demonstrado na Tabela 3, esta Área de Planejamento foi a que mais sofreu alterações na cobertura verde, concentrando mais de $70 \%$ do total apurado.

\subsubsection{Relação entre denúncias de infrações ambientais e características das regiões administrativas: uma análise quantitativa}

A Tabela do Anexo 1 apresenta os quantitativos de denúncias de infrações ambientais por RA; verifica-se que as regiões da Barra da Tijuca, Jacarepaguá, Campo Grande e Guaratiba representam mais de $60 \%$ de todas as infrações. Um possível motivo para isso pode ser a especulação imobiliária nestas áreas. Em relação às duas primeiras, localizadas na AP4, o PMMA-Rio (Rio de Janeiro, 2014) já havia ressaltado que nestas áreas está ocorrendo uma urbanização de modo acelerado, no qual os principais atores são os segmentos de classe social alta e média. É possível perceber que, com exceção da RA da Cidade de Deus, as demais regiões apresentam os maiores índices de denúncias do Município. Estas áreas, situadas na AP4, também representam 
quase $40 \%$ da Mata Atlântica da Cidade (Tabela 4) e, devido a isso, há um alto número de denúncias de desmatamento e de loteamentos e ocupações irregulares. Nota-se que as regiões administrativas de Santa Cruz, Bangu, Campo Grande, Guaratiba e Realengo (que compõem a Área de Planejamento 5) apresentam índices acima da média de 11,7 infrações por região administrativa (373 - número total de infrações na tabela do Anexo 1, dividido por 32 - número de regiões administrativas), com destaque para Campo Grande e Guaratiba. O que está de acordo com Malta et al. (2017), que afirma que a maior parte desta AP está classificada como alta vulnerabilidade ambiental. Isso ocorre porque a maior parte desta região encontra-se em loteamentos irregulares e favelas (Rio de Janeiro, 2014). Além disso, boa parte da área verde da Cidade está concentrada nesta área.

A Tabela do Anexo 2 apresenta características relacionadas ao índice de progressão social e a expectativa de aumento populacional das regiões administrativas do município do Rio de Janeiro. A partir da análise de regressão linear múltipla entre o total de denúncias de infrações ambientais por região administrativa e as 13 características de cada região administrativa, verificou-se que o único modelo (ver Tabela 5) que se apresentou razoável foi aquele em que os totais de denúncias são explicados pelas variáveis "moradia", "segurança" e "expectativa de aumento populacional". O valor do

TABELA 5 - Resultados de Regressão Múltipla.

\begin{tabular}{|c|c|c|c|c|c|c|}
\hline \multicolumn{2}{|c|}{ Resumo Dos Resultados } & & & & & \\
\hline $\mathrm{R}$ múltiplo & 0,8091716 & & & & & \\
\hline R-Quadrado & 0,6547587 & & & & & \\
\hline R-quadrado ajustado & 0,6177686 & & & & & \\
\hline Erro padrão & 12,59479 & & & & & \\
\hline \multicolumn{7}{|l|}{ ANOVA } \\
\hline & $G l$ & $S Q$ & $M Q$ & $F$ & $F$ de signif.. & \\
\hline Regressão & 3 & 8423,6142 & 2807,8714 & 17,7009 & $1,219 \mathrm{E}-06$ & \\
\hline Resíduo & 28 & 4441,6045 & 158,62873 & & & \\
\hline Interseção & $-45,06083$ & 11,50828 & $-3,9155138$ & 0,0005268 & $-68,634474$ & $-21,487187$ \\
\hline Moradia & 0,3722239 & 0,1225083 & 3,0383568 & 0,0051077 & 0,121277 & 0,6231708 \\
\hline Segurança Pessoal & 0,2831622 & 0,1125417 & 2,5160658 & 0,0178782 & 0,0526311 & 0,5136933 \\
\hline $\begin{array}{l}\text { Expectativa de au- } \\
\text { mento populacional }\end{array}$ & 118,03593 & 17,393514 & 6,7862039 & $2,269 \mathrm{E}-07$ & 82,406935 & 153,66493 \\
\hline
\end{tabular}

FONTE: Os autores. 
R-quadrado ajustado $(0,617769)$ indica que $62 \%$ da variação dos quantitativos de denúncias são explicados pelas três variáveis. $\mathrm{O}$ valor de $\mathrm{F}$ de teste bem superior ao $\mathrm{F}$ de significação indica que é possível desprezar a hipótese de que os coeficientes da equação de regressão (ângulos) sejam todos iguais a zero, o que também se confirma pelos valores-P destes coeficientes que são todos menores que 0,05 . Os coeficientes das três variáveis explicativas são todos positivos, o que significa que à medida que os valores destas variáveis aumentam, aumentam também os quantitativos de denúncias.

A relação positiva entre as variáveis "moradia" e "segurança" sugere que os danos ambientais também podem ocorrer em áreas onde residem pessoas com alto e médio poder aquisitivo, e não apenas nas áreas de favelas. Este resultado indica que Souza (2015) está correto ao afirmar que a Política Ambiental deve ser para todos, e não apenas para as comunidades, uma vez que há condomínios e mansões que também degradam o meio ambiente. Por outro lado, estes resultados apontam também para uma maior capacidade de realizar denúncias por parte de moradores de bairros com melhores indicadores de "moradia" e "segurança". É possível que, nestas áreas, as pessoas não se sintam coagidas ao acusar as irregularidades ambientais. Logo, isso explica o porquê de as regiões de favelas não terem feito nenhuma queixa, mesmo sendo áreas de alta incidência de infrações. Verifica-se também que a maior parte da explicação, cerca de $42 \%$, deve-se à variável "expectativa de crescimento populacional". Este resultado está de acordo com a literatura, que afirma que o aumento populacional de forma desorganizada gera uma sobrecarga sobre os recursos naturais.
A seguir foram realizadas nove regressões múltiplas entre os quantitativos de denúncias de cada tipo de infração ambiental por região administrativa (variável dependente ou explicada) e as 13 características de cada região administrativa (variáveis independentes ou explicativas).

Uma análise dos valores R-quadrado, $\mathrm{F}$ de teste e valores-P alcançados mostra que, no caso das infrações DIR, FLO, HID, LOI e OCI, a única variável explicativa relevante é a "expectativa de aumento populacional". Este resultado está de acordo com o que fora apresentado pelas autoras Nunes \& Bastos (2018). Elas afirmam que, apesar de a população das cidades ter crescido, o investimento em infraestrutura foi insuficiente. Isso motivou diversas pessoas a desmatarem (FLO) para residir em favelas e Loteamentos (LOI) e Ocupações Irregulares (OCI). Além disso, o crescimento populacional aumentou a quantidade de resíduos produzidos. Entretanto, o tratamento do lixo e do esgoto ainda não é suficiente e eficaz em toda a Cidade. Consequentemente, há a intensificação das denúncias de DIR e HID.

Por outro lado, a variável "expectativa de aumento populacional" não é capaz de explicar outros três tipos de denúncias (ASL, EMI e SLO). No que concerne às denúncias de ASL, a não explicação se deve ao fato de este tipo de irregularidade não possuir relação lógica com a Expectativa de Aumento Populacional. Já em relação à EMI e a SLO, uma explicação para a ausência de correlação significativa seria o fato de que houve poucos registros destes tipos de denúncia, as quais, somadas, representam apenas $3 \%$ do total apurado.

Com relação à infração ATM, verifica-se que ela é explicada de forma relevante pelas variáveis "moradia", "segurança pessoal" e "Acesso à infor- 
mação e comunicação", esta última com coeficiente negativo. Em relação às variáveis "moradia" e "segurança pessoal", pode significar que esses indicadores apontam na verdade uma maior capacidade de denunciar estas infrações ambientais da Cidade. No que diz respeito ao "acesso à informação e comunicação", o coeficiente negativo representa que quanto maior o acesso, menos denúncias há na região. Este resultado pode significar que nestas áreas há realmente uma ocorrência menor de infrações, devido à falta de conhecimento sobre a importância da manutenção do meio ambiente.

Finalmente, ressalve-se que, a partir dos dados das tabelas dos Anexos 1 e 2, verifica-se que quanto maior a expectativa de aumento populacional, maior a quantidade de infrações. Neste sentido, Nazareth (2018) destaca que quando o crescimento ocorre de modo desordenado, aumenta a desigualdade, uma vez que a parcela da população acaba ocupando áreas onde não há tratamento de esgoto e do lixo. Consequentemente, causam danos ambientais e colocam suas próprias vidas em risco.

\subsubsection{Relação entre denúncias de}

infrações ambientais e grupos de regiões administrativas: uma análise qualitativa

As Regiões Administrativas da Cidade do Rio de Janeiro foram divididas inicialmente por níveis de renda domiciliar nominal per capita obtidos pelo Censo Demográfico de 2010, conforme a Tabela 6.

Foram considerados como bairros de renda alta as Regiões Administrativas que apresentaram renda domiciliar nominal per capita acima da média do município em todos os extratos da população avaliados. As regiões cuja renda domiciliar nominal per capita ficou acima da média nos primeiro, segundo, terceiro e quarto quintos mais pobres, foram consideradas renda média. As demais RAs foram consideradas como renda baixa.

A partir dos dados da Tabela 6, quantidade de denúncias, vulnerabilidade ambiental e indicadores de progresso social de cada região administrativa, as mesmas foram agrupadas em seis grupos conforme a Figura 4. Para cada um destes seis grupos, foram feitas a seguir considerações sobre as denúncias encontradas nas RA que compõem cada grupo.

O Grupo A é composto pelas regiões administrativas da Barra da Tijuca e de Jacarepaguá, localizadas na AP 4 e apresentaram os maiores índices de Expectativa de Aumento Populacional. Estas Regiões Administrativas também são as que mais possuem denúncias ambientais. Conforme a Tabela do Anexo 2, elas também têm notas inferiores à média do Município no quesito "Água e Saneamento", o que explica altos índices de despejo irregular de resíduos (DIR) e de poluição hídrica (HID). Assim, percebe-se que estas são regiões críticas em relação à qualidade ambiental do município, apesar da boa situação econômica e social de seus habitantes. A alta expectativa de aumento populacional, somada à grande quantidade de áreas verdes, ao baixo investimento em água e saneamento e ao elevado número de denúncias, revela que estas áreas estão entre as principais a serem fiscalizadas. Este resultado está de acordo com o encontrado pelo PMMA-Rio (Rio de Janeiro, 2014), o qual acrescenta que os atores desse crescimento são integrantes das classes sociais média e alta provenientes da Área de Planejamento 2 da Cidade. Assim, é possível concluir que os bons níveis de educação não são necessariamente sinônimos de qualidade ambiental. Entretanto, o conhecimento é importante para que as pessoas 
TABELA 6 - Indicadores de renda.

\begin{tabular}{|c|c|c|c|c|c|c|}
\hline RA & $\begin{array}{c}\text { Renda do } 1^{\circ} \\
\text { quinto mais } \\
\text { pobre }\end{array}$ & $\begin{array}{c}\text { Renda do } 2^{\circ} \\
\text { quinto mais } \\
\text { pobre }\end{array}$ & $\begin{array}{c}\text { Renda do } 3^{\circ} \\
\text { quinto mais } \\
\text { pobre }\end{array}$ & $\begin{array}{c}\text { Renda do } 4^{\circ} \\
\text { quinto mais } \\
\text { pobre }\end{array}$ & $\begin{array}{c}\text { Renda do quinto mais } \\
\text { rico }\end{array}$ & $\begin{array}{c}\text { Classificação } \\
\text { do nível de } \\
\text { renda }\end{array}$ \\
\hline Rio de Janeiro & 119,71 & 359,79 & 619,38 & 1167,21 & 4905,41 & - \\
\hline Portuária & 46,05 & 239,63 & 395,12 & 569,54 & 1275,83 & Baixa \\
\hline Centro & 274,17 & 643,93 & 991,86 & 1608,87 & 4139,27 & Média \\
\hline Copacabana & 308,53 & 1126,78 & 2205,71 & 4054,18 & 11617,63 & Alta \\
\hline Lagoa & 309,99 & 1576,83 & 3508,86 & 6016,81 & 17485,38 & Alta \\
\hline São Cristóvão & 58,55 & 259,41 & 457,07 & 726,36 & 2063,12 & Baixa \\
\hline Tijuca & 287,49 & 919,11 & 1781,68 & 3042,93 & 9094,08 & Alta \\
\hline Penha & 88,07 & 325,58 & 541,03 & 881,08 & 2252,34 & Baixa \\
\hline Inhaúma & 70,45 & 332,82 & 566,11 & 903,62 & 2388,78 & Baixa \\
\hline Méier & 145,61 & 489,79 & 862,28 & 1471,99 & 3808,94 & Média \\
\hline Irajá & 170,59 & 421,87 & 684,55 & 1125,83 & 2852,16 & Média \\
\hline Madureira & 149,09 & 374,93 & 585,24 & 917,99 & 2335,46 & Baixa \\
\hline Jacarepaguá & 161,09 & 418,91 & 698,30 & 1248,83 & 3831,88 & Média \\
\hline Bangu & 77,93 & 278,54 & 456,95 & 702,20 & 1722,14 & Baixa \\
\hline Campo Grande & 123,64 & 315,24 & 504,06 & 786,31 & 2029,12 & Baixa \\
\hline Guaratiba & 59,87 & 220,52 & 370,20 & 593,50 & 1538,82 & Baixa \\
\hline Rocinha & 50,14 & 242,36 & 383,83 & 557,23 & 1043,66 & Baixa \\
\hline Jacarezinho & 43,60 & 202,67 & 318,39 & 484,41 & 977,55 & Baixa \\
\hline C. do Alemão & 56,53 & 212,48 & 319,19 & 470,45 & 895,44 & Baixa \\
\hline Maré & 93,21 & 243,69 & 365,82 & 536,34 & 1044,34 & Baixa \\
\hline Vigário Geral & 52,01 & 250,46 & 431,61 & 684,60 & 1735,31 & Baixa \\
\hline Realengo & 133,22 & 337,19 & 537,92 & 850,87 & 2411,24 & Baixa \\
\hline Cidade de Deus & 121,44 & 273,84 & 390,61 & 571,70 & 1229,60 & Baixa \\
\hline
\end{tabular}

FONTE: IBGE. Microdados da Amostra do Censo Demográfico de 2010. Cálculos e tabulação: IPP. 


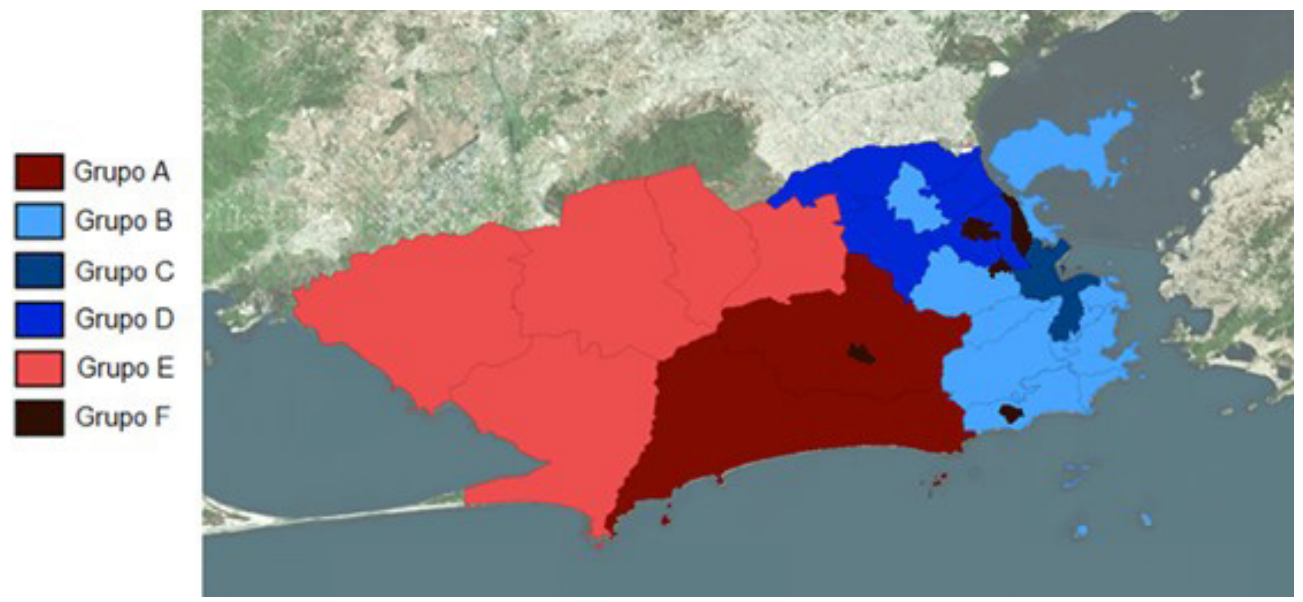

FIGURA 4 - Representação dos Grupos no mapa.

FONTE: Os autores.

saibam quais tipos de denúncias ambientais existem e quais órgãos procurar. O Grupo A revela que, sem o investimento em infraestrutura e fiscalização do Poder Público, não há qualidade ambiental. De modo que a atuação estatal é fundamental para garantir que as áreas verdes remanescentes, assim como as áreas de restingas e os recursos hídricos, sejam preservados.

No Grupo B estão as demais RAs de classe social média (Centro, Méier, Irajá, Ilha do Governador e Santa Teresa) e alta (Botafogo, Copacabana, Lagoa, Tijuca e Vila Isabel). São regiões com boa infraestrutura, uma vez que, de acordo com a Tabela do Anexo 2, todos os componentes do grupo apresentaram notas acima da média em relação à variável "moradia". Além disso, quanto à "água e Saneamento", apenas a RA do Centro não atingiu a nota média do município. Vale ressaltar que os componentes do grupo apresentaram notas satisfatórias nos quesitos "Acesso à Educação Superior", "Aceso ao Conhecimento Básico" e "Aceso à Informação e à Comunicação". Além de possuírem baixa expectativa de aumento populacional e poucas denúncias de infrações ambientais (exceto Botafogo e Ilha do Governador, cujo quantitativo foi um pouco acima da média). Assim, é possível concluir que o baixo número de denúncias reflete a realidade destas áreas, ou seja, provavelmente, não há muitas infrações nestes locais. Isto acontece porque são áreas que já foram degradas há muitos anos. Logo, o principal tipo de infração da região é poluição atmosférica e, em algumas regiões, a poluição hídrica. Em relação à RA da Tijuca, é importante a realização de projetos de prevenção ao desmatamento no bairro do Alto da Boa Vista, onde está localizado o Parque Nacional da Tijuca, que representa grande parcela da área de verde da Cidade.

Pode-se inferir que grande parte dos investimentos foi direcionado para a AP2 no passado. Como resultado disto, há uma pequena quantidade de denúncias e áreas com qualidade de vida acima da média da Cidade. Entretanto, devido ao esgota- 
mento de terras nestas áreas, parte significativa da população optou por se mudar para os bairros que compõem o Grupo A.

O grupo C é composto pelas Regiões Administrativas de classe baixa da AP1 (Portuária, Rio Comprido e São Cristóvão). O crescimento da Cidade do Rio de Janeiro ocorreu, inicialmente, nos bairros próximos ao Centro. Atualmente, as classes altas e médias estão se mudando para a AP4. Entretanto, a Área de Planejamento 1 continua com alta expectativa de aumento populacional, conforme a Tabela do Anexo 2. Estas áreas costumam ser procuradas por pessoas de classe baixa, devido ao pouco investimento em infraestrutura. Isso pode ser constatado na Tabela do Anexo 2, que apresenta o desempenho ruim nas variáveis "Moradia", "Segurança Pessoal", "Acesso ao Conhecimento Básico", "Acesso à Educação Superior” e "Tolerância e Inclusão". Recentemente, o Poder Público realizou a revitalização da região Portuária e incentivou o aumento populacional do local. Destaca-se que a pouca infraestrutura, o elevado aumento populacional e o baixo acesso à educação de forma geral indicam que é possível que existam mais infrações ambientais na região do que o sugerido pela quantidade de denúncias na Tabela do Anexo 1.

O Grupo D compõe-se pelas seguintes Regiões Administrativas: Ramos, Penha, Inhaúma, Madureira, Anchieta, Pavuna e Vigário Geral, que são regiões de classe baixa localizadas na Área de Planejamento 3. Apesar de apresentarem bons resultados em "Água e Saneamento", o mesmo não ocorre com "Saúde e Bem-estar", "Liberdade Individual” e “Acesso à Educação Superior”. Há baixa expectativa de aumento populacional e poucas denúncias de infrações ambientais. Além disso, não há muitas áreas verdes nestas regiões. Sendo assim, é possível concluir que, efetivamente, não há muitas infrações de LOI, OCI e FLO. Nestas áreas, as principais infrações que ocorrem são o despejo irregular de resíduos (DIR) e a poluição atmosférica (ATM).

No grupo E, estão todas as RAs localizadas na Área de Planejamento 5 (Santa Cruz, Bangu, Campo Grande, Guaratiba e Realengo). Esta é uma das regiões mais críticas da Cidade, especialmente Santa Cruz e Guaratiba, onde, segundo a Tabela do Anexo 2 , há alta expectativa de aumento populacional, grande quantidade de denúncias ambientais e baixos níveis em "Água e Saneamento" e "Moradia”. Além disso, esta AP concentra a maior parte da área verde da Cidade (Tabela 5) e mais de $70 \%$ do total das alterações na cobertura verde da Cidade (Tabela 4). Outra característica da região é o baixo desempenho em "Acesso à Informação e Comunicação", "Sustentabilidade dos Ecossistemas", "Liberdade Individual" e "Acesso à Educação Superior".

O Grupo F é composto pelas RAs do Complexo do Alemão, Rocinha, Jacarezinho, Maré e Cidade de Deus, as quais são áreas de favelas e não apresentaram nenhuma denúncia de infrações ambientais. Entretanto, a literatura informa que é comum existirem vários tipos de infrações ambientais, por exemplo: ocupações irregulares, despejo irregular de resíduos (porque a empresa responsável pela limpeza urbana presta um serviço que é insuficiente nestas regiões), ausência de esgotamento sanitário, realização de queimadas, entre outros. Além disso, todas apresentam os quesitos: "Moradia", "Acesso ao Conhecimento Básico", "Liberdade Individual e de Escolha" e "Acesso à Educação Superior" abaixo da média da Cidade (Tabela do Anexo 2). Logo, é possível considerar que um dos motivos para a ausência de denúncias seja a falta de co- 
nhecimento sobre a importância da preservação do meio ambiente. Vale considerar também que estas comunidades estão sujeitas a um poder paralelo, que é exercido por traficantes e milicianos, o que pode pressionar os residentes dessas áreas a não denunciarem eventuais irregularidades por medo de represálias ou por conhecerem a baixa probabilidade de algum representante estatal ir até lá verificar a possível infração. Estas áreas costumam apresentar alto grau de expectativa de aumento populacional, com destaque para a Rocinha (29\%) e a Maré (20\%). Diferentemente do Grupo A, esse crescimento não costuma ser devido às migrações de outras regiões, mas sim devido à alta taxa de natalidade dessas áreas. Ao combinar estes fatores, percebe-se que o número de denúncias de infrações ambientais não representa a situação da área.

\subsection{Considerações finais}

O Grupo A é o responsável por $55 \%$ das denúncias de infrações do período registrado (Figura 2). Esse resultado revela que, apesar de serem bairros de classe média-alta e apresentarem índices satisfatórios em "Educação Superior", são regiões ambientalmente críticas, principalmente devido à elevada concentração de área verdes na Região e à alta expectativa de aumento populacional. Segundo o PMMA-Rio (Rio de Janeiro, 2014), esta é uma região que está sendo moldada por ocupações de encostas e desmatamento, o que está de acordo com o que foi encontrado.

O Grupo B também é composto por bairros de classe média-alta, entretanto, há uma quantidade muito menor de infrações ambientais. A diferença entre o Grupo A está ligado a dois fatores. O primeiro é que, como esta região da Cidade fora urbanizada anteriormente, devido à proximidade à RA do Centro, houve investimento em "Água e saneamento" no local, de modo que as ocupações formais não causassem tanta degradação ambiental. O segundo fator diz respeito a não existirem tantas áreas verdes na região (com exceção do bairro do Alto da Boa Vista), uma vez que a ocupação desses locais já ocorreu há bastante tempo.

No que tange ao Grupo C, vê-se que, apesar de refletir apenas $2 \%$ do total de infrações (Figura 2), o baixo investimento em infraestrutura, o elevado aumento populacional e o baixo acesso à educação de forma geral sugerem que existam mais infrações ambientais do que a quantidade registrada. De acordo com essa informação, o PMMA-Rio (Rio de Janeiro, 2014) corrobora a importância dos recursos hídricos da região, que são constantemente poluídos tanto por moradias quanto por empresas e embarcações.

O Grupo D apresentou poucas denúncias, as quais são, em sua maioria, relativas ao despejo irregular de resíduos (DIR) e à poluição atmosférica (ATM). Por serem regiões com baixas concentrações de área verde, os principais tipos de irregularidades são as que independem da presença de recursos naturais. Vale destacar que o baixo acesso à educação superior e à saúde e bem-estar são indicativos da necessidade de conscientização ambiental na região para reduzir a incidência destas irregularidades.

No Grupo E encontra-se boa parte das denúncias ambientais localizadas, principalmente nas RAs de Guaratiba e Campo Grande. Algumas características, como alta concentração de áreas verde, pouco acesso à educação de forma geral, altíssima expectativa de aumento populacional e pouca infraestrutura em "Água e Saneamento" e "Moradia", 
indicam a possibilidade de esta ser uma região com mais infrações ambientais do que o Grupo A, apesar de o registro de denúncia indicar o contrário. Além disso, a maior parte das alterações da cobertura verde da Cidade ocorreu na AP5 (71,2\%) (Tabela 4), sendo mais um indicativo de que esta seja uma das regiões mais críticas da Cidade. Entretanto, há mais denúncias de loteamento irregulares (LOI) e desmatamentos (FLO) nas regiões do Grupo A. Tal situação revela que analisar apenas os registros de denúncias - sem levar em conta outras características sociais e econômicas das regiões - não costuma ser suficiente para verificar a vulnerabilidade ambiental destas.

Os Grupos E e F possuem características sociais parecidas, pois são locais de classe de renda baixa com indicadores abaixo da média, de modo geral em "Nutrição e Cuidados Médicos Básicos", "Acesso à Educação Superior", "Sustentabilidade dos ecossistemas", "Liberdade individual e de escolha" e "Tolerância e inclusão" (Tabela do Anexo 2). Além disso, são regiões que a literatura aponta como pontos críticos da Cidade, em relação à qualidade ambiental e aos riscos de desabamento. Entretanto, a quantidade de denúncias entre uma e outra é bem diferente. Enquanto o Grupo E apresenta 31\% das denúncias (Figura 2), as favelas do Grupo $\mathrm{F}$ não apresentam nenhuma (Tabela do Anexo 1). A Tabela 7 revela as diferenças entre estes grupos com o objetivo de identificar a razão de não haver nenhuma denúncia nas regiões de favelas (Tabela do Anexo 2).

A partir da Tabela 7, pode-se perceber que, em relação às variáveis "Moradia" e "Acesso ao Conhecimento Básico", apesar de os dois grupos terem obtido notas abaixo da média da Cidade, há uma diferença de mais de 30 pontos entre eles. Em relação ao "Acesso à Educação Superior", destaca-se que a média obtida pelo Grupo $\mathrm{F}$ equivale a menos de $10 \%$ da média da Cidade. Esses resultados discrepantes são consequências, segundo Nazareth (2018), do modelo de urbanização excludente, o qual marginaliza as populações mais pobres. Com relação ao indicador segurança pessoal, talvez os critérios (taxa de homicídio e roubos de rua) utilizados para seu levantamento estejam produzindo números melhores do que a realidade das favelas. Neste sentido, o PMMA-Rio (Rio de Janeiro, 2014, p. 230) elenca como um obstáculo à gestão ambiental a ausência de segurança pública, de modo que "não é possível delinear um Cenário de Desenvolvimento sem que haja uma adequação na Política de Segurança Pública do Estado do Rio de Janeiro". A percepção dos autores indica que os indicadores "água e saneamento" e "saúde e bem-estar" não representam a realidade do Grupo F, uma vez que estes locais são historicamente conhecidos pela falta de acesso ao saneamento básico e serviços públicos de saúde.

\section{Conclusões}

O presente trabalho analisou de forma quantitativa e qualitativa as denúncias de infrações ambientais enviadas pelo Ministério Público Estadual à Prefeitura da Cidade do Rio de Janeiro. Incialmente foi analisado o registro de denúncias do banco de dados interno da Gerência de Monitoramento e Fiscalização Ambiental da Cidade do Rio de Janeiro, o qual é o objetivo principal do trabalho. A partir destas informações, identificou-se que os tipos mais comuns de infração são os desmatamentos (FLO) e os loteamentos irregulares (LOI), que representam quase metade das denúncias. Também foi analisado 


\begin{tabular}{|c|c|c|c|c|}
\hline & Média Grupo E (AP5) & $\begin{array}{c}\text { Média Grupo F } \\
\text { (Favelas) }\end{array}$ & Diferença & Média Cidade \\
\hline Nutrição e Cuidados Médicos Básicos & 67,186 & 47,376 & 19,81 & 67,28 \\
\hline Moradia & 70,732 & 39,132 & 31,6 & 72,80 \\
\hline Segurança Pessoal & 64,544 & 73,798 & $-9,254$ & 64,50 \\
\hline Acesso à informação e comunicação & 30,336 & 35,328 & $-4,992$ & 49,21 \\
\hline Saúde e bem-estar & 52,464 & 72,208 & $-19,744$ & 60,69 \\
\hline Sustentabilidade dos ecossistemas & 42,912 & 44,926 & $-2,014$ & 49,39 \\
\hline Direitos individuais & 65,376 & 56,37 & 9,006 & 61,27 \\
\hline Expectativa de aumento populacional & $15 \%$ & $12 \%$ & $3 \%$ & $9,6 \%$ \\
\hline
\end{tabular}
FONTE: Os autores.

o total de infrações por Áreas de Planejamento. Foi possível identificar que as regiões que concentram as queixas são as AP4 e AP5.

Em um segundo momento, foram feitas regressões lineares entre 13 características (12 indicadores de progresso social e a expectativa de crescimento populacional) das Regiões Administrativas da $\mathrm{Ci}$ dade (variáveis independentes) e as quantidades de denúncias ambientais (variáveis dependentes). Os resultados das regressões sugerem que, quanto maior a expectativa aumento populacional, mais denúncias. Esse resultado está de acordo com a literatura estudada, que afirma que o crescimento desordenado da Cidade, tanto pela população de classe média-alta quanto pela classe de renda baixa, causa muitos danos ambientais, principalmente sob a forma de desmatamentos e loteamento irregulares. Os resultados também sugerem que regiões com altos indicadores uma maior propensão a denunciar as irregularidades.

Em um terceiro momento, as RAs foram agrupadas em seis grupos e foi possível concluir que nas áreas onde há investimento em infraestrutura de esgotamento sanitário, moradia e acesso à educação, há poucas infrações ambientais. Entretanto, quando algum destes atributos não está presente, há grandes chances de a área tornar-se ambientalmente vulnerável. Nas regiões onde há alta expectativa de crescimento da população, há ainda mais riscos aos recursos naturais, mesmo quando existem poucas ou nenhuma denúncia registrada.

A partir do exposto, entende-se que é importante registrar e analisar as denúncias de infrações ambientais, pois elas são capazes de fornecer dados importantes sobre a dinâmica de ocupação e uso do solo. Entretanto, ainda não há conscientização da necessidade de relatar a ocorrência destes danos ao 
meio ambiente em todas as regiões da Cidade. Logo, a avaliação apenas das queixas torna-se insuficiente para retratar o cenário da qualidade ambiental e das áreas de risco do Rio de Janeiro. Recomenda-se, portanto uma maior divulgação dos canais de atendimento dos órgãos públicos responsáveis e a realização de programas de conscientização da população, pois a educação ambiental é capaz de mudar a percepção do cidadão, de modo que este perceba que faz parte do contexto da natureza (Nunes \& Bastos, 2018).

É possível identificar como limitações do estudo o número não tão expressivo de denúncias em regiões ambientalmente críticas da Cidade. Devido a isso, ressalta-se a necessidade do aumento da participação popular nas decisões do Governo, que representa a Governança, a qual é capaz de aumentar a efetividade dos instrumentos de planejamento da Cidade. Bento et al. (2018) corroboram este posicionamento, ao afirmar que a participação popular se dá tanto no processo decisório quanto no cotidiano, por meio da consciência ambiental e das denúncias.

Assim, é aconselhável que o monitoramento das infrações continue sendo realizado, e que as ações fiscalizatórias não ocorram apenas com base nas denúncias, principalmente nas áreas mais críticas, onde o número de queixas não representa a qualidade ambiental do local. Recomenda-se, ainda, que avaliações como esta sejam feitas periodicamente, com a finalidade de acompanhar a efetividade, a eficácia e a eficiência dos programas ambientais.

\section{Referências}

Aguiar, A. de O. Estratégias e ações estratégicas nos Planos Municipais da Mata Atlântica: estudo documental em seis municípios. Desenvolvimento e Meio Ambiente, 50, 234253, 2019. doi: 10.5380/dma.v50i0.58967
Bento, S. C.; Conti, D. de Melo; Baptista, R. M.; Ghobril, C. N. As Novas Diretrizes e a Importância do Planejamento Urbano para o Desenvolvimento de Cidades Sustentáveis. Revista de Gestão Ambiental e Sustentabilidade, 7(3), 469488, 2018. doi: 10.5585/geas.v7i3.1342

Bernardino, D.; Franz, B. Lixo flutuante na Baía de Guanabara: passado, presente e perspectivas para o futuro. Desenvolvimento e Meio Ambiente, 38, 231-252, 2016. doi: 10.5380/dma.v38i0.47024

Borinelli, B. As Características dos problemas ambientais e suas implicações para a política ambiental. Serviço Social em Revista, 13(2), 63-84, 2011. doi: 10.5433/1679-4842.2011v13n2p63

Brasil. Constituição da República Federativa do Brasil de 5 de outubro de 1988. São Paulo: Atlas, 49. ed., 2020.

Brasil. Lei Complementar n. ${ }^{\circ} 140$, de 8 de dezembro de 2011. Fixa normas, nos termos dos incisos III, VI e VII do caput e do parágrafo único do art. 23 da Constituição Federal. Brasília: DOU de 9/2/2011, Seção 1.

Brasil. Lei $n^{\circ}{ }^{\circ}$ 12.651, de 25 de maio de 2012. Dispõe sobre a proteção da vegetação nativa; altera as Leis n. ${ }^{\circ} 6.938$, de 31 de agosto de 1981, 9.393, de 19 de dezembro de 1996, e 11.428, de 22 de dezembro de 2006; revoga as Leis n. ${ }^{\circ} \mathrm{s}$ 4.771, de 15 de setembro de 1965, e 7.754, de 14 de abril de 1989, e a Medida Provisória n. ${ }^{\circ} 2.166-67$, de 24 de agosto de 2001; e dá outras providências. Brasília: DOU de 28/5/2012.

Bursztyn, M. A.; Bursztyn, M. Fundamentos de política e gestão ambiental: caminhos para a sustentabilidade. Rio de Janeiro: Garamond, 2012.

Câmara, J. B. D. Governança ambiental no Brasil: ecos do passado. Sociologia e Política, 21(46), 125-146, 2013. doi: 10.1590/S0104-44782013000200008

CONEMA - Conselho Estadual de Meio Ambiente. Resolução $n .^{\circ} 42$, de 17 de agosto de 2012. Dispõe sobre as atividades que causam ou possam causar impacto ambiental local. Rio de Janeiro: DOE - RJ de 28/08/2012.

Creswell, W. Projetos de pesquisa: métodos qualitativo, quantitativo e misto. Porto Alegre: Bookman, 3. ed., 2016.

Fernandes, V.; Malheiros, T. F.; Philippi Jr, A.; Sampaio, A. C. Metodologia de avaliação estratégica de processo 
de gestão ambiental municipal. Saúde e Sociedade, 21(3), 128-143, 2012. doi: 10.1590/S0104-12902012000700011

Fiorillo, C. A. P. Curso de direito ambiental brasileiro. São Paulo: Saraiva, 13. ed., 2012.

GMFA-7 - Gerência de Monitoramento da Biodiversidade Subsecretaria de Meio Ambiente. Programa de Monitoramento da Cobertura Vegetal, 2018. Disponível em: <http:// www.rio.rj.gov.br/dlstatic/10112/6438610/4221813/75ProgramadeMonitorame ntodaCoberturaVegetal.pdf $>$. Acesso em: abr. 2019.

Honda, S. C. de A. L.; Vieira, M. do C.; Albano, M. P.; Maria, Y. R. Planejamento ambiental e ocupação do solo urbano em Presidente Prudente (SP), urbe.Revista Brasileira de Gestão Urbana, 7(1), 62-73, 2015. doi: 10.1590/21753369.007.001.AO04

INEA - Instituto Estadual do Ambiente. Boletins de Qualidade das Águas por Região Hidrográfica. Rio de Janeiro, RJ. Disponível em: <http://www.inea.rj.gov.br/ar-agua-e-solo/qualidade-das-aguas-por-regiao-hidrografica-rhs/>. Acesso em: mar. 2019.

IPP - Instituto Pereira Passos. Projeção Populacional 20132020 para a Cidade do Rio de Janeiro: uma aplicação do método AiBi. Coleção Estudos Cariocas, 20130102, 2013. Disponível em: http://portalgeo.rio.rj.gov.br/estudoscariocas/download/3255_Proje\%C3\%A7\%C3\%A3oPopulacional2013-2020_CidadedoRiodeJaneiro_m\%C3\%A9todoAiBi.pdf. Acesso em: mar. 2019.

IPP - Instituto Pereira Passos. Índice De Progresso Social No Rio De Janeiro, 2016. Disponível em: <http://ipsrio. com.br/publicacao>. Acesso em: fev. 2019.

Malta, F. S.; Costa, E. M.; Magrini, A. Índice de vulnerabilidade socioambiental: uma proposta metodológica utilizando o caso do Rio de Janeiro, Brasil. Ciência \& Saúde Coletiva, 12, 3933-3944, 2017. doi: 10.1590/1413812320172212.25032017

Minayo, M. C. S.; Sanches, O. Quantitativo-Qualitativo: Oposição ou Complementaridade? Cadernos de Saúde Pública, 9(3), 239-262, 1993

Nazareth, P. A. Planos Diretores e Instrumentos de Gestão Urbana e Ambiental no Estado do Rio de Janeiro. Revista do Serviço Público, 69(1), 211-240, 2018. doi: 10.21874/ rsp.v69i1.1762

Nunes, A. C. T.; Bastos, V. P. Políticas Públicas de Sustentabilidade Urbana no Gerenciamento de Resíduos Sólidos. O Social em Questão, 40, 253-266, 2018. Disponível em: http://osocialemquestao.ser.puc-rio.br/media/OSQ_40_ art_11_Nunes_Bastos.pdf

Pedreira, L. O. L.; Andrade, F. N.; Brasiliano, V. F. Nota Técnica $-n^{\circ} 37$ Índices de Áreas Verdes do Município do Rio de Janeiro. Rio de Janeiro: Prefeitura do Rio de Janeiro, 2017. doi: 10.13140/RG.2.2.19062.29764

Pizella, D. G. A relação entre Planos Diretores Municipais e Planos de Bacias Hidrográficas na gestão hídrica. Revista Ambiente e Água, 10(3), 635-645, 2015. doi: 10.4136/ ambi-agua.1394

Rio de Janeiro (Município). Anexo Técnico I: Informações Sobre Todas As Áreas de Planejamento Coordenação Operacional de Atendimento Em Emergências (Emergência Presente). Rio de Janeiro: Prefeitura do Rio de Janeiro, 2006. Disponível em: <http://www.rio.rj.gov.br/ dlstatic/10112/1529762/DLFE-220205.pdf/1.0 $\geq$. Acesso em: mar. 2019.

Rio de Janeiro (Município). Plano Municipal de Conservação e Recuperação da Mata Atlântica do Rio de Janeiro (PMMA-Rio). Rio de Janeiro: Prefeitura do Rio de Janeiro, 2014. Disponível em: <https:/www.data.rio/ datasets/3f105a10dcf7475eae69b2514b9d6262 $\geq$. Acesso em: mar. 2019.

Rio de Janeiro (Município). Mapeamento da Cobertura e do Uso das Terras do Rio de Janeiro, 2016. Disponível em: <https://www.rio.rj.gov.br/web/smac/exibeconteudo? $\mathrm{id}=2367968 \#: \sim:$ text $=\mathrm{O} \% 20$ mapeamento $\% 20 \mathrm{da} \% 20$ cobertura $\% 20$ vegetal,os $\% 20$ conhecimentos $\% 20$ das $\% 20$ ci\%C3\%AAncias\%20naturais>. Acesso em jun. 2019.

Rio de Janeiro (Município). Decreto n. ${ }^{\circ} 43.137$, de 15 de maio de 2017. Dispõe sobre as competências da Secretaria Municipal de Conservação e Meio Ambiente - SECONSERMA. Rio de Janeiro: DOE de 16/05/2017, 2017 a.

Rio de Janeiro (Município). Decreto no 43.372, de 30 de junho de 2017. Regulamenta a Lei Municipal no 6.179 de 22 de maio de 2017, que dispõe sobre medidas para o 
combate eficaz à poluição sonora no Município do Rio de Janeiro e dá outras providências. Rio de Janeiro: DOE de 03/07/2017, 2017b.

Rio de Janeiro (Município). Mapas das Áreas de Planejamento (AP) e Regiões Administrativas (RA) do município do Rio de Janeiro. Rio de Janeiro: Prefeitura do Rio de Janeiro, 2017c. Disponível em: <http://www.rio.rj.gov.br/ web/smac/pmma-rio $\geq$. Acesso em: mar. 2019.

Souza, M.L. Proteção ambiental para quem? A instrumentalização da ecologia contra o direito à moradia. Mercator, 14, 25-44, 2015. doi: 10.4215/RM2015.1404.0003
Stanganini, F. N.; Lollo, J. A. de. O crescimento da área urbana da cidade de São Carlos/SP entre os anos de 2010 e 2015: o avanço da degradação ambiental. Urbe.Revista Brasileira de Gestão Urbana, 10(1), 118-128, 2018. doi: 10.1590/2175-3369.010.supl1.ao14.

STF - Supremo Tribunal Federal. Repercussão Geral no RE $n^{\circ}$ 586.224, Relator Min. Luiz Fux, julgado em 05/03/2015. DJE de 08/05/2015. Disponível em: <http://www.stf.jus. br/>. Acesso em: jun./2019.

Vergara, S.C. Projetos e Relatórios de Pesquisa em Administração. São Paulo: Editora Atlas, 2. ed., 1998. 
Anexo 1

TABELA - Quantitativos de denúncias.

\begin{tabular}{|c|c|c|c|c|c|c|c|c|c|c|}
\hline $\mathbf{R A}$ & ASL & ATM & DIR & EMI & FLO & HID & LOI & OCI & SLO & Total \\
\hline Portuária & 0 & 0 & 1 & 0 & 0 & 2 & 0 & 0 & 0 & 3 \\
\hline Centro & 0 & 1 & 0 & 0 & 0 & 0 & 0 & 0 & 0 & 1 \\
\hline Botafogo & 0 & 3 & 0 & 0 & 6 & 0 & 0 & 3 & 0 & 12 \\
\hline Copacabana & 1 & 5 & 0 & 0 & 1 & 0 & 0 & 0 & 0 & 7 \\
\hline São Cristóvão & 0 & 0 & 1 & 0 & 0 & 0 & 1 & 0 & 0 & 2 \\
\hline Tijuca & 0 & 5 & 0 & 0 & 0 & 1 & 1 & 0 & 0 & 7 \\
\hline Vila Isabel & 0 & 0 & 1 & 0 & 1 & 0 & 0 & 0 & 0 & 2 \\
\hline Ramos & 1 & 1 & 2 & 0 & 0 & 0 & 0 & 0 & 0 & 4 \\
\hline Irajá & 0 & 1 & 1 & 0 & 1 & 0 & 0 & 0 & 0 & 3 \\
\hline Madureira & 1 & 4 & 0 & 0 & 0 & 1 & 1 & 0 & 0 & 7 \\
\hline Jacarepaguá & 5 & 9 & 4 & 4 & 23 & 4 & 8 & 8 & 2 & 67 \\
\hline Bangu & 1 & 3 & 6 & 0 & 1 & 1 & 3 & 0 & 1 & 16 \\
\hline Campo Grande & 1 & 7 & 3 & 0 & 8 & 0 & 15 & 3 & 0 & 37 \\
\hline Santa Cruz & 1 & 5 & 2 & 0 & 0 & 0 & 6 & 1 & 0 & 15 \\
\hline Ilha do Governador & 2 & 2 & 2 & 0 & 6 & 0 & 0 & 0 & 0 & 12 \\
\hline Anchieta & 0 & 3 & 2 & 0 & 0 & 0 & 0 & 0 & 1 & 6 \\
\hline Jacarezinho & 0 & 0 & 0 & 0 & 0 & 0 & 0 & 0 & 0 & 0 \\
\hline C. do Alemão & 0 & 0 & 0 & 0 & 0 & 0 & 0 & 0 & 0 & 0 \\
\hline Maré & 0 & 0 & 0 & 0 & 0 & 0 & 0 & 0 & 0 & 0 \\
\hline Vigário Geral & 0 & 3 & 1 & 0 & 0 & 0 & 0 & 0 & 0 & 4 \\
\hline Realengo & 1 & 3 & 3 & 0 & 2 & 1 & 6 & 2 & 0 & 18 \\
\hline Cidade De Deus & 0 & 0 & 0 & 0 & 0 & 0 & 0 & 0 & 0 & 0 \\
\hline Total & 20 & 64 & 46 & 5 & 95 & 19 & 85 & 33 & 6 & 373 \\
\hline
\end{tabular}

FONTE: Banco de Dados interno GMFA (2018). 
TABELA - Características de cada RA.

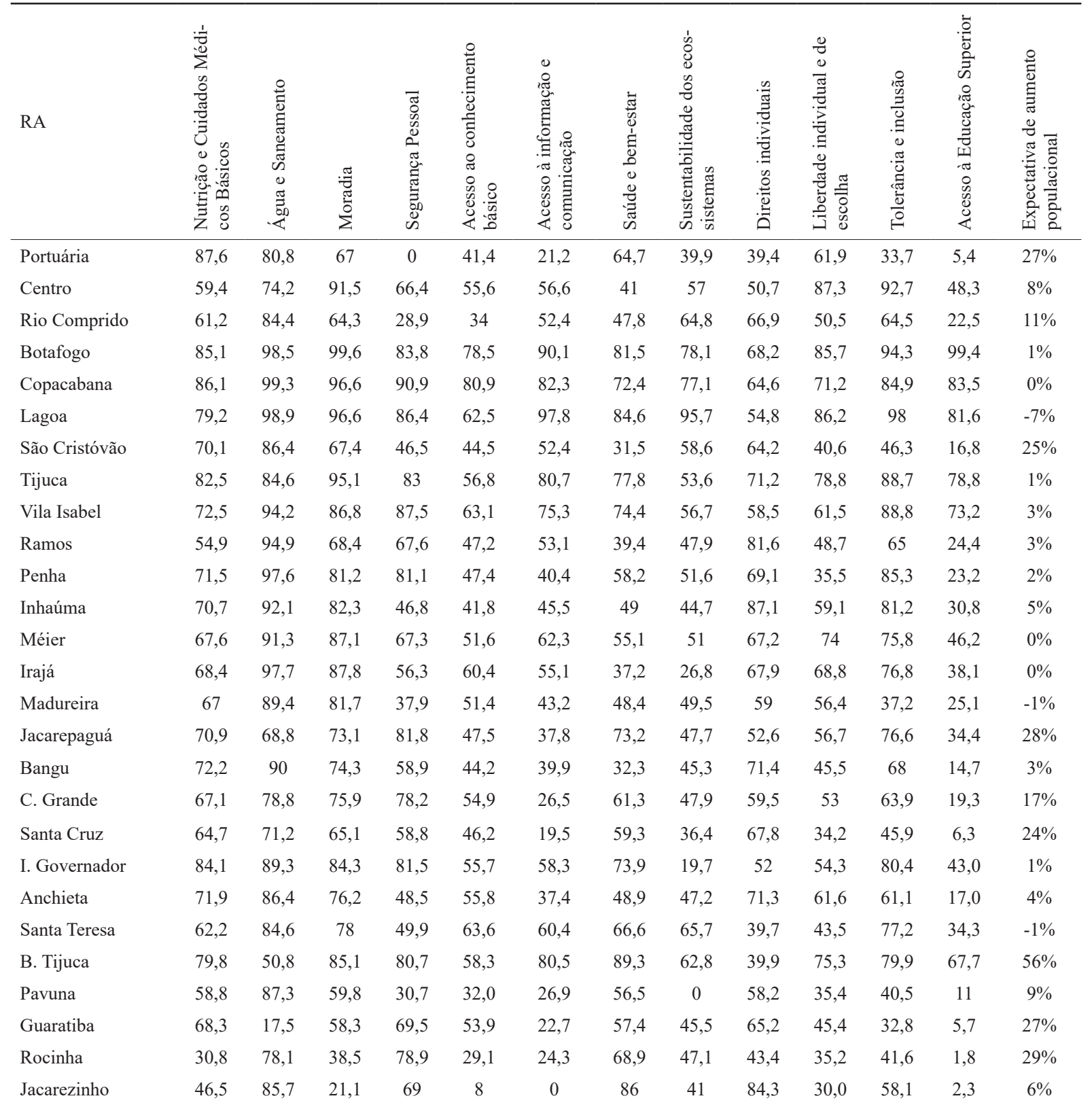




\begin{tabular}{|c|c|c|c|c|c|c|c|c|c|c|c|c|c|}
\hline C. do Alemão & 57,0 & 93 & 19,3 & 77,4 & 0 & 38,8 & 75 & 47,3 & 45,9 & 7,36 & 68 & 0,5 & $10 \%$ \\
\hline Maré & 70,1 & 82,2 & 52,4 & 70,9 & 24,4 & 53,0 & 88,5 & 48,3 & 53,8 & 29,9 & 52,3 & 2,3 & $20 \%$ \\
\hline Vigário Geral & 68,7 & 88,6 & 70,7 & 68,7 & 38,6 & 36,9 & 47,4 & 45,2 & 67,9 & 26,6 & 64,1 & 12,3 & $1 \%$ \\
\hline Cidade De Deus & 32,5 & 93,4 & 64,4 & 72,9 & 36,1 & 60,5 & 42,8 & 41 & 54,6 & 23,2 & 53,9 & 4,5 & $-7 \%$ \\
\hline Total & 67,3 & 84,3 & 72,8 & 64,5 & 47,5 & 49,2 & 60,7 & 49,4 & 61,3 & 51,9 & 66,5 & 31,1 & $9,6 \%$ \\
\hline
\end{tabular}

FONTE: Índice de Progresso Social no Rio de Janeiro (IPP, 2016) e Expectativa de aumento populacional (elaboração própria a partir dos dados de IPP, 2013). 